\title{
INTERRELACIÓN EXISTENTE ENTRE LOS PRINCIPIOS DEL NUEVO CÓDIGO PROCESAL PENAL Y LA CONSTITUCIÓN POLITICA
}

Evton Jean ORteci
Fiscal Auxiliar de Managua
Ministerio Público

L

a reciente entrada en vigencia del Código Procesal Penal, constituye sin lugar a dudas un paso significativo en la lucha por alcanzar un verdadero Estado de Derecho, en donde al ciudadano sometido a proceso se le garanticen efectivamente los derechos que permitan hacerle frente a la imputación que se le hace. No se pueden abordar los principios que inspiran al nuevo régimen procesal, sin hacer necesaria referencia a los principios y garantías consignadas en la Carta Magna, la que como norma fundamental permite el desarrollo normativo de los mismos.

\section{Derecho de los detenidos}

Los artículos 33 y 34 Cn, consagran los derechos y garantías mínimos qute amparan a cualquicr detenido $y / 0$ procesado.

El citado artículo $33 \mathrm{Cn}$, establece que la detención de un ciudadano sólo podrá efectuarse en virtud de mandamiento escrito de Juez competente, de las autoridades expresamente facultadas por la ley, o en caso de flagrancia. En virtud de lo anterior según el CPP, tratándose de detención ordenada judicialmente ésta procederá en los casos del 266 CPP, o sea, cuando ha sido presentada acusación por el Ministerio Público, si la persona acusada se encuentra en libertad, puede el fiscal solicitar la detención del ciudadano sometido a proceso para que comparezca a la celebración de la audiencia inicial.

La detención en caso de flagrancia y por mandato policial, está regulada en la forma y términos que a tal cfeclo fija el Arto. 33Cn. El precepto constitucional en referencia, garantiza así mismo, el derecho a ser informado de las causas de 
su detención en el idioma que éste entienda, a comunicarle la mismá a sus familiares $y$ a ser tratado con el respeto inherente al ser humano.

Estos derechos encuentran recepción en el artículo 95 CPP incisos 2, 3, 11 y en el párrafo segundo de ese nismo artículo, que de manera expresa establecen que todo imputado tiene derecho a ser informado de las causas de su detención, comunicarse con tun familiar o abogado a quien informar su detención; ser asistido por un intérprete si no comprende o no habla el idioma empleado por el tribunal y deberá en todo caso ser tratado por la Policía Nacional con las debidas garantías indivictuales respetándole su dignidad humana.

Especial atención merece la referencia de la norma constitucional en estudio en lo que hace al respeto de la dignidad humana del detenido, a tal efecto, tenemos que el artículo 3 CPP garantiza este respeto a la dignidad humana no sólo para el procesado, detenido o imputado; sino a toda persona que de una u otra forma se vea involucrada en el proceso penal. Este respeto a la dignidad humana es sin lugar a dudas un principio meta jurídico que subyace en la raíz misma de la civilización humana.

Otro referente importante del artículo 33 constitucional, es que todo detenido tiene que ser puesto en libertad o a la orden de autoridad competente dentro del plazo de cuarenta y ocho horas posteriores a su detención.

Este plazo constitucional de cuarenta y ocho horas, constituye cl límite máximo de detención de una persona sin existir un proceso judicial en su contra; de tal manera que, tanto la Policía Nacional como el Ministerio Público, deben coorđinar sus esfuerzos para realizar una investigación que permita a éste último órgano, determinar si existe mérito para ejercer la acción penal. De ser así, la Policía deberá según el artículo $231 \mathrm{CPP}$, presentar al detenido en el plazo constitucional ante el Juez competente y el Ministerio Público de conformidad al artículo 256 de ese mismo Código, deberá presentar acusación dentro del término de cuarenta y ocho horas para la celebración de la correspondiente audiencia preliminar.

Si durante el plazo de cuarenta y ocho horas, no existe una investigación que permita al fiscal presentar actusación, deberá éste proceder de acuerdo al principio de objetividad que informa su actuación y en fiel cumplimiento del artículo 88 CPP ${ }^{1}$, solicitarle al jefe policial poner en libertad al detenido, en razór de haberse cumplido el plazo constitucional de detención, a como efectiva-

1 Arto. 88. Respeto a las Garantías. En el ejercicio de la acción penal Publica, el Ministerio Publico deberá guardar el más absoluto respeto a los derechos y Garantías consagrados en la Constitución Política, los tratados y convenios internacionales relativos a los derechos humanos ratificados por Nicaragua y los establecidos en este código. 
mente puede verse en la doctrina fiscal contenida en el prontuario ${ }^{2}$ en las respuestas a las preguntas números 17 y 19

\section{Derechos de los procesados}

Estos derechos y garantías procesales de] procesado, encuentran configuración legal en el artículo 34 Cn, veremos si el Código Procesal Penal, responde a las exigencias consagradas en la citada noma constitucional.

\subsection{Presunción de Inocencia}

La presunción o estado de inocencia, supone gue toda persona es inocente mientras no se compruebe su culpabilidad en un proceso. Nuestra norma suprema, exige que el dictado de esta culpabilidad corresponde exclusivamente al órgano jurisdiccional que llega a tal conclusión, solamente a través de um proceso penal en el que se han observado todas las garantías y formalidades que el mismo exige.

De conformidad al artículo 2 del Código Procesal Penal, la presunción o estado de inocencia ampara al imputado en todo momento del proceso, mientras no se declare su culpabilidad mediante sentencia firne dictada conforme a la ley. En este sentido, cl prolesor Víctor Gimeno Sendra, estima que "la presunción de inocencia está, pues, presente a lo largo de todas las fases del proceso penal y de todas stus instancias, una de las conquistas esenciales del movimiento liberal, consistió en elevar a rango constitucional el derecho de todo ciudadano, sometido a un proceso penal a ser presumido inocente" 3

La presunción de inocencia, implica que, corresponde al órgano acusador incorporar al proceso las pruebas demostrativas de la culpabilidad del acusado, no estando sujeto este último a probar st inoccncia, se convierte entonces en una regla de juicio mediante la cual la carga de la prueba recae en el órgano postulante de la acusación.

Una derivación importante de este estado constitucional de inocencia del acusado, es que cuando en un proceso no se haya demostrado su culpabilidad y, aunque tampoco se haya llegado a demostrar en el proceso la inocencia del misno, procede dictar la absolución de éste, esto es lo que se denomina el IN

2 Es el Ijbro en el que están contenidas las respuestas a las preguntas más frecuentcmente consultadas al Departamento de Asesoría Técnica del Ministerio Ptiblico por parte de los fiscales en relación al nuevo Código Y'rocesal Penal.

3 Gimeno Sendra Vicente, Cortes Dominguez y Moreno Catena. Derecho Procesal Penal. Editorial COLEX, Madrid España, 1977. Pág. 94. 
DUBIO PRO REO, es decir que la falta de certeza sobre la realización del hecho imputado, deriva en el dictado de una sentencia favorable al acusado, resultando preferible la absolución de un culpable que la condena de un inocente.

La presunción o estado de inocencia que ampara a todo acusado por tun ilícito penal, solamente puede ser desvirtuada cuando:

- Haya certeza de la culpabilidad, obtenida de la prueba practicada y valorada.

- Dicha actividad probatoria haya sido incorporada lícitamente al proceso.

- La valoración de la prueba debe ser efectuada por el juzgador, utilizando como base el criterio racional y proporcional con que la misma fue producida en juicio.

\section{Derecho a Juez natural y celeridad procesal}

En el enunciado segundo del Arto. $34 \mathrm{Cn}$., se garantiza el derecho de ser procesado sin dilaciones ante tribunal competente establecido por la ley. La recepción procesal de esta garantía constitucional, la encontramos en Ios artículos 8 y 11 CPP, los que respectivamente consagran los principios de celeridad procesal y Juez natural.

Articulo 8: principio de gratuidad y celexidad procesal "... toda persona acusada en un proceso penal tiene derecho a obtener una resolución en un plazo razonable, sin formalismos que perturben sus garantías constitucionales".

Articulo 11: Juez Natural. Nadie podrá ser juzgado por otros jueces que los designados conforme a ley anterior a los hechos por los que se les juzga. En consecuencia, nadie puede ser sustraído de su Juez competente establecido por ley ni llevado a jurisdicción de excepción. Se prohiben los tribunales especiales.

El principio de Juez Natural, se constituye como un elemento esencial del concepto de debido proceso, ya que a como señala Fernando Tocora "lo primero en efecto, que define la legalidad del proceso es la legitimidad del Juez y esa legitimidad está dada por la natural competencia que la Constitución le ha asignado" +

4 Tocora Fernando. Política Criminal en América Latina, Ediciones Librería del Profesional, Bogotá Colombia, 1990. Pág. 5. 
El derecho a Juez legal importa la obligación de que dicho juzgador tiene que estar previamente determinado de conformidad a normas de competencia igualmente preestablecidas. Constituye una garantía en el sentido de que es el órgano jurisdiccional y no cualquier otra autoridad o institución pública o privada, la que tiene encomendada la función de juzgar a través de un tribunal independiente e imparcial establecido de conformidad a las normas comunes de conpctencia pre establecidas. Ello implica la proscripción de órganos jurisdiccionales creados con posterioridad a la comisión del hecho que se pretende enjuiciar.

La consagración del principio derecho a un juez natural, da cabida a dos importantes aspectos: uno positivo según el cual el precepto constitucional atribuye el cerecho tanto al que reclama la tutela judicial como al ajusticiado, a que su causa sea conocida por un Juez previanente predeterminado por la ley; otro negativo la prohibición constitucional de tribunales de excepción o ad hoc, los que se crean para conocer determinado caso, y valga aclarar que se crean después de la comisión del acto ilícito.

El der echo a una justicia pronta y sin dilaciones, consagrado tanto en la norma constitucional como en la procesal penal, pretende sentar las bases de un verdadero Estado de derecho, en donde ya no es posible la ocurnencia del fenómeno denomina do o conocido como "presos sin condena", en los que producto del formalismo escrito del anterior sistema inquisitivo, los jueces y demás operadores del sistema de justicia, obstaculizaban y retrasaban los procesos con lo que se impedía el derecho del procesado a una tutela judicial efectiva.

Es importante destacar que el legislador patrio ha considerado la celeridad en la aplicación de la justicia, no como un enunciado formal, sino, que, lo ha consagrado como un auténtico pilar de un verdadero Estado de derecho. Ello se traduce en la queja por retardación que de conformidad al artículo $133 \mathrm{CPP}$ puede interponer el interesado ctando los representantes del Ministerio Público o los jueces no cumplen con los plazos cstablecidos para la realización de sus funciones.

\section{Derecho a ser sometido a juicio por jurado}

En el anterior sistema inquisitivo, se regulaba también el derecho del acusado a que la decisión final acerca de su inocencia o culpabilidad fuera determinada por un tribunal de jurados. La diferencia con el actual sistema acusatorio estriba en que antes, el acusado no podía renunciar a ese detecho, renuncia que con el actual sistema sí es posible, pues así lo regula expresamente el artículo 293 del Código Procesal Penal en su segundo párrafo que reza así: el acusado con derecho a ser juzgado por jurado puede renunciar a dicho derecho y ser juzgado por el juez de la causa. 
Cabe hacer mención de que la institución del jurado tiene una doble vertiente: descle el punto de vista del acusado constituye un derecho renunciable y desde la óptica del ciudadano que será miembro del Tribunal de Jurados, constituye una exigencia constitucional estatuida en el Arto 51 Cn. "es deber del ciudadano desempeñar los cargos de Jurados... "5

\section{Derecho a la defensa}

El nuevo sistema de procedimiento penal concibe al imputado no como un mero objeto del proceso, sino, como un sujeto del proceso, ello significa que éste debe estructurarse de tal manera que, siempre tenga la posibilidad de intervenir cn aquellos actos que puedan afectar sus derechos, así, para GIOVANNI LEONE, "el derecho a la defensa es un derecho inviolable en todo estado y grado del procedimiento, constituye ante todo el derecho del imputado a la notificación de la acusación" " siendo evidente que sería casi totalmente ineficiente un derecho a defenderse sin saber de que acusación hay que hacerlo.

El derecho a la defensa se desglosa en dos aspectos, la denominada defensa material, o sea, la defensa actuada por el imputado mismo y defensa formal o técnica, esto es, la defensa actuada por el defensor.

Los incisos 4 y 5 del artículo $34 \mathrm{Cn}$. garantizan la intervención y defensa del acusado desde el inicio del proceso y el derecho a tener un defensor sea de oficio o de carácter privado, convirtiéndose así la defensa en un derecho inviolable en cada estado y grado del procedimiento.

El derecho de defensa se materializa en una serie de derechos que hacen posible que el acusado no quede en estado de indefensión que es lo que en definitiva trata de garantizar el nuevo sistema procesal penal, es por ello que procesalmente hablando, los artículos 95, 101 y 103 CPP desarrollan nomativamente el adecuado ejercicio de la defensa material y técnica que ha sido previamente garantizada en el antes referido articulo $34 \mathrm{Cn}$.

Es derecho del acusado presentarse en cualquier momento ante e] Minisstexio Público, Policía o Juez, para que se le escuche y alegue sobre la acusación en su contra; en caso de ser detenido se le debe informar los motivos de la misma, dobe ser presentado ante el Juez en el término de cuarenta y ocho horas.

5 Constitución Politica de Nicaragua. Arto. 51. Pág. 39.

6 Leone Giovanni. Tratado de Derecho Procesal Penal, Tono I, Doctrinas Generales, Traducción de Sentis Melendo, Edición Jurídica, Europa América, Buenos Aires, 1963 Pảg. 564 y Sig. 
REVISTA DE DILRLCHO

Frente al ejercicio de la acción en el proceso penal, cuyo titular es la parte acusadora, el ordenamiento jurídico reconoce el derecho del acusado a obtener igualmente tutela efectiva por medio de una adecuada defensa que garantice una recta administración de justicia para el imputado.

El acusado para poder intervenir de manera cficaz en el proceso, necesita conocer la acusación que en su contra se formula, es por ello que como parte integral del derecho de defensa en el inciso 6 del citado artículo $34 \mathrm{Cn}$, se garantiza el nombramiento de un intérprete, si el acusado no comprende o no habla el idioma empleado por el Tribunal, igual regulación se encuentra en el artículo 95 inciso $11 \mathrm{CPP}$.

El reconocimiento constitucional del derecho de defensa como derecho fundamental, exige que el mismo "sea reconocido no solo cuando se haya formulado acusación dentro del jujcio oral, sino desde el instante en que el procedimiento se dirija contra una determinada persona, imputándole la comisión de un hecho delictivo y debe salvaguardarse a lo largo de todas las actuaciones procesales. ${ }^{7}$

\section{Derecho a no declarar contra sí mismo}

La presunción o estado cle inocencia exige que sea el órgano acusador quien provea los elementos necesarios para sostener la acusación y lograr un eventual pronunciamiento de culpabilidad del actsado.

La prohibición constitucional a la que me refiero se encuentra establecida en el artículo 34 inciso $7 \mathrm{Cn}$, encuentra su desarrollo normativo procesal en el artículo 95 inciso 1.2 CPP. La consagración constitucional de esta garantía, se refiere al "reconocimiento del principio jurídico general del que nadie puede ser constreñido a accionar en su propio daño, de manera que no se puede obligar al imputado a que confiese st propia culpabilidad ni aún siquiera a responder al interrogatorio".s

Considero que existe igual prohibición, respecto de aquella persona que originalmente no figura como acusada o imputada, sino que, lo hace en calidad de testigo, aunque posteriormente pueda adquirir dicha condición. En tal caso, debe extenderse esa protección a ese testigo que por su relación con los hechos

7 Sendra Gimeno, Vicente, Moreno Catena, Cortés Domínguez Valentín. Derecho procesal Penal, 3er edición. Editorial Colex.- 1999. Pág. 1.11.

8 Vicenzo Manzini y otros. Tratado de Derecho procesal Penal, Tomo II. Edición de Cultura Jurídico. Pág. 58. 
o con la persona acusada, pueda considerarse posteriormente como acusada, esa garantía se encuentra expresamente configurada en el artículo 196 último párrafo, en donde claramente se establece que ningún testigo estará obligado a declat rar sobre hechos que le puedan deparar responsabilidad penal a sí mismo.

\section{Derecho a la doble instancia}

Los artículos 34 inciso $9 \mathrm{Cn}$ y el $17 \mathrm{CPP}$, tutelan el derecho del acusado que ha sido encontrado culpable de la comisión de un delito de recurrir ante un tribunal jerárquicamente superior al que dictó la resolución que le depara perjuicio, a fin de que esta sea revisada. El derecho al recurso significa que toda persona declarada culpable de un delito tendrá derecho a que el fallo condena torio y la pena que se le haya impuesto sean sometido a un tribunal superior conforme lo prescrito por la ley.

El derecho a los recursos, al igual que cualquier otro derecho fundamental no es un derecho absoluto, es por ello que el artículo 17 CPP, garantiza el mismo en los casos previstos en dicho Código. La no absolutes de ese derecho encuentra su configuración procesal en el principio de taxatividad consagrado en el artículo 361 CPP, el que en su tenor literal expresa: las decisiones judiciales serán recurribles sólo por los medios y en los casos expresamente establecidos.

\section{A no ser procesado nuevamente}

El derecho a no ser nuevamente procesado, consagrado en los artículos 34 inciso $10 \mathrm{Cn}$ y artículo $6 \mathrm{CPP}$, constituye una garantía que protege la libertad individual, implica no solamente el impedimento de una nueva persecución por los mismos hechos por los que el acusado ha resultado condenado, sino que, también dicha garantía cubre los supuestos de sentencias absolutorias dictadas a favor del acusado y sobre los cuales se pretende ejercer nuevamente el ius puniendi. Con ello se pretende que el proceso penal en su conjunto alcance un necesario grado de certeza. Viene a conslituir en palabras de Vives Antón" "un derecho fundamenta1 del individuo encuadrable dentro de la noción de proceso justo, o equitativo como parte indispensable del mismo y que pretende en última instancia ser una garantía del derecho a la dignidad humana, impidiendo el sometimiento de un enjuiciamiento reiterado y sucesivo de una persona"

Los alcances de este derecho son de carácter restringido de manera que no cabe ser invocado por un coimputado porque el sobrescimiento o en su caso la sen-

9 Vives Antón, Tomás NE BIS IN IDEM PROCESAL. Los principios del proceso penal. Consejo general del poder judicial. Madrid 1992, pag11). 
tencia absolutoria a favor de un procesado no puede ser invocados por éste, contra quien se inicia proceso ya sea ante la misma judicatura o en otra. Este coimputado no puede alegar ni la declaración de inexistencia del hecho ni aún la declaración de su no autoría o participación contenida en una resolución. dictada en un proceso en el cual no fue parte.

En este sentido, Fernando de la Rua, ${ }^{10}$ sostiene el criterio de que este derecho solamente se puede hacer valer si concurren las siguientes condiciones: a) la existencia de una imputación originaria; b) que quien fue objeto de ella haya astumido el papel de imputado, es decir haya sido efectivamente perseguido y c) que se trate de la misma persona, perseguida bajo una segunda imputación tácticamente igual a la primera.

\section{Principio de legalidad}

El principio de legalidad cuyo origen es debido a Beccaria y es expresado con la máxima "nıllum crimen, nulla poena, sine lege", supone que sólo la ley previa aprobada por el Parlamento, y no por el Poder Ejecutivo ni el Judicial, pueden definir las conductas que se consideren delictivas y establecer sus penas. Ello significa la proscripción de leyes penales ex post facto, exigiéndose en consecuencia la preexistencia de la norma sancionadora con relación al hecho investigado. Lo anterior nos lleva a considerar que "toda conducta que no esté prevista en la hipótesis genérica y abstracta de la ley penal, cae fuera de la puntuación del círculo represivo, queda en la zona de libertad ${ }^{\prime \prime 11}$

Como derivación de este principio de legalidad penal, encontramos el principio de legalidad procesal, consagrado en el articulo 1 del CPP, en virtud del cual, nadie puede ser condenado a una pena o someticto a una medida de seguridad sino mediante una sentencia firme diclada por un tribunal competente en un proceso conforme a los derechos y garantías consagrados en la Constitución y las leyes.

Mediante la judicialización de la pena o medida de seguridad, el legislador pretende advertir que para la imposición de las mismas, se necesita la realización de un procedimiento de investigación y discusión en el que se respete la inviolabilidad de la defensa y se verifique una valoración crítica y fundada por parte del Juez de los elementos fácticos y jurídicos de los cuales ha de extraer su decisión, o sea, la fundamentación lógica de la sentencia.

10 De la Rúa Fernando, Lerner, editores asociados. Procesos y Justicia, Temas procesa les, Buenos Aires 1980. P’ág. 97.

11 Ob. Cit por: Femando de la Rua, Pág. 303. 
Una derivación importante de este principio de legalidad procesal, lo constituye el hecho de que, para que la decisión judicial sea válida, no basta que sea emitida por un Juez, sino que, debe ser dictada por uno que tenga competencia funcional y territorial previamente asignada por la ley procesal penal, a tal efecto, deberán seguirse las reglas contenidas en el Título I, Capítulo II, artículos $20 \mathrm{y}$ siguientes del CPP.

\section{Principio de publicidad}

Se encuentra regulado en la parte final del inciso 12 del artículo $34 \mathrm{Cn}$ y en el artículo $13 \mathrm{CPP}_{r}$ y viene a constituirse en garante de que, la ejecución o práctica de la prueba, se realice mediante la posibilidad de asistencia o presencia física, no sólo de las partes, sino de la sociedad en general.

La publicidad del juicio oral, como bien advierte Moreno Catena se convierte en una "garantía de necesaria observancia cual es la de que el juicio a que todo acusado tiene derecho ha de ser público, no solo para él mismo, quien ha de poder presenciar todas las sesiones, sino tambiên para todos los mienbros de la sociedad que quieran asistir a su realización" ${ }^{\prime 2}$

Los límites a que está sujeto este principio, se encuentran trazados en cl artículo $13 \mathrm{CPP}$, el que en la parte final de su primer pártafo refiere que la publicidad puede ser limitada por las causas previstas en la Constitución y las leyes. Estas, generalmente obedecen a consideraciones de moralidad, orden público, protección a la vida privada de las partes o a la integridad de algunos sujetos procesales, pero a su vez constittiyen un freno a los juicios paralelos, en los que a través de los medios de comunicación se difama a la persona acusada con el único objeto de presionar a la opinión publica a fin de predeteminar un eventual fallo condenatorio en contra del acusado, limitación que en iguales condiciones ha sido advertida por Moreno Catena. ${ }^{13}$

\section{Principio acusatorio}

Encuentra su consagración en el artículo 10 del CPP ${ }^{14}$ y en el se marcan los ejes característicos del sistema de enjuiciamiento de corte acusatorio, estos son:

12 Ob. Cit. Víctor Moreno. Derecho Procesal Penal. Pág. 91.

13 Lan de operar siempre como límites frente a los tristemente famosos "juicios paralelos" en los que a través de un medio de comunicación, más que ejercitar el derecho deber de transmitir información veraz, de lo que se trata es de difamar a la persona acusada con el único objeto de presionar a la opinión pública a fin de minar la independencia del Tribunal. Víctor Gimeno Sendra, Victor Moreno Catena, Valentín Cortés Domínguez, Derecho Procesal Penal, 3 edición 1999, Pág. 94.

14 Principio acusatorio. El ejercicio de la acción penal es distinto del de la función jurisdiccional. En consecuencia; los jueces no podrán proceder a la investigación, persectición ni acusación de ilícitos penales. 
a) El proceso propiamente dicho se inicia por persona distinta a la del Juez, no puede existir proceso sin acusación previa formulada por persona distinta a la del juzgador. Con ello se pretende garantizar su imparcialidad, de manera que el material fáctico tiene que ser aportado por las partes y, el Juez, ha de decidir basándose en los principios de contradicción y congruencia, pues de otro modo obviamente queda comprometida su imparcialidad.

b) No cabe condena por hechos distintos ni persona distinta a la señalada en la acusación. Esta segunda manifestación, es derivada de la anterior en el sentido de que vincula al juzgador a respetar los extremos objetivos y subjetivos de la acusación, concretada en la correlación que debe existir entre la acusación y la sentencia, a como en efecto se dispone en el artículo $157 \mathrm{CPP}$, pues de lo contrario estaríamos en presencia de un sostenimien to indirecto de la pretensión penal por parte del órgano jurisdiccional.

c) Prohibición de reforma en perjuicio, que no es más que la prohibición dirigida al órgano jurisdiccional de agravar la situación del acusado cuando solamente éste haya recurrido en alzada haciendo tso de los recursos que la ley establece en aras de alcanzar una mejor situación jurídica.

En este sistema, el acusador ha de ser necesariamente persona distinta del Juez, pues de otro modo no existe verdadero proceso. Resulta absolutamente compatible con la necesidad de perseguir públicamente los delitos el imperativo jurídico de que el proceso sea imparcial y justo. Es de trascendental importancia no encomendar ambas tareas a la misma persona. Es preciso además que el juicio se desarrolle sin que el Juez tone parte junto al acusador en una supuesta búsqueda de la verdad material, comprometiendo así la imparcialidad y no puede sustituirlo en su función acusadora si aquel abandona el juicio antes de haber formulado la acusación.

La 1iltima ratio del proceso acusatorio es la de preservar la imparcialidad del Juez, para que este sea un auténtico juzgador supra partes, sin que le competa la función de perseguix los delitos cometidos, sino sólo la de juzgar si se han cometido o no, según las pruebas que hayan sido aportadas por las partes. Esto constituye una garantía imprescindible de la imparcialidad del Juez y esta a su vez es una garantía de la justicia del juicio, criterio que a su vez es sostenido por Maeir. ${ }^{15}$

15 "La característica fundamental del enjuiciamiento acusatorio reside en la división de los poderes que se ejercen en el proceso, por un lado el acusador, que persigue penalmente y ejerce el poder requirente por el otro diel imputado quien puede resistir la imputación ejerciendo el derecho de la defensa y, finalmente el tribunal que tiene en sus manos el poder de decidir. El principio fundamental que da nombre al sistema acusatorio se afirma en la exigencia de un tribunal para decidir el pleito y los limites de su decisión están condicionados al reclamo o acusación". 
Una nota característica del principio acusatorio lo es la exigencia entre la correlación que debe existir entre la acusación y sentencia, misma que subsiste ya sea en segunda o sucesivas instancias, de manera que no se puede gravar más al apelante de lo que ya lo estaba en virtud de la sentencia recurrida, por lo que no le resulta dable al tribunal superior aumentar la pena impuesta en primera instancia, cuando ésta haya sido impugnada solamente por el acusado o su defensor, o sea que existe la prohibición de reforna en perjuicio consagrada en el artículo $371 \mathrm{CPP}, 16$

En este sentido, el profesor Víctor Gimeno Sendra, expresa que ${ }^{17}$ "al igual que es necesario el establecimiento de la referida correlación subjetiva y objetiva o vinculación temática en la primera instancia, la vigencia del principio acusatorio exige que en las segundas o sucesivas instancias no se pueda gravar más a un apelante de lo que ya lo estaba por la sentencia recurrida, salvo que el apelado impugne también independientemente la sentencia o se adhiera a la apelación ya iniciada, de tal suerte que el órgano ad -quem ha de estar vinculado por los limites subjetivos y objetivos trazados por la acusación y la defensa en la segunda instancia".

La interrelación existente entre los principios que informan el Código Procesal Penal y los derechos y garantías constitucionales que hacen alusión al debido proceso y a los derechos del procesado, constituye sin lugar a equívoco la entrada de nuestro país al concierto de naciones respetuosas de los derechos y garantías del procesado, y por otra parte el abandono del oscurantismo del sistema inquisitivo con todas sus consecuencias perniciosas, de manera que, a como expresa Goldschmidt $t^{15}$, "en definitiva, lo que define a una sociedad es su derecho y, especialmente, su Derecho Procesal Penal es reflejar fielmente las tendencias autoritarias o democráticas de una sociedad, pues revela la relación existente entre los ciudadanos y el poder".

16 Prohibición de reforma en perjuicio. En los recursos de apelación y casación, cuando la decisión haya sido impugnada únicamente por el acusado o su defensor, no podrá ser modificada en su perjuicio. Los recursos interpuestos por cualquiera de las partes permitirán modificar o revocar la decisión a favor del acusado.

17 Gimeno Sendra, Vicente Moreno Catena, Cortés Domínguez Vatentín. Derecho Procesal Penal Ber edición Editorial Colex, 1990. Pảg. 87.

18 Cuellar Cruz Rigoberto, La Reforma Procesal Penal del Ministerio P'úblico en Honduras. Justificación y Perspectivas, Talleres Litográficos de impresión S.D.R.L. Tegucigalpa Honduras 2001 . 


\section{BIBLIOGRAFIA}

- Constitución Política de Nicaragua.

- Código Procesal Penal.

- Ley Orgánica del Ministerio Público.

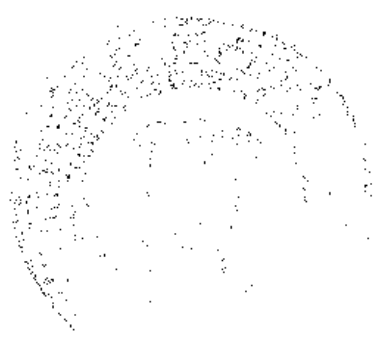

Prontuario.

- Apuntes de clases de maestría en Derecho Penal y Procesal Penal. UCA. 2002.

- Cuéllar Cruz Rigoberto. La Reforma Procesal Penal del Ministerio Público en Honduras. Justificación y perspectiva. Talleres Litográficos de Impresión s. d. r. 1. Tegucigalpa Honduras. 2001.

- De la Rúa Fernando, Lemer editores asociados. Proceso y Justicia, Temas Procesales. Buenos Aires. 1980.

- Gimeno Sendra Vicente, Cortés Domínguez y Moreno Catena, Derecho Procesal Penal. Editorial Colex, Madrid España. 1997.

- Gimeno Sendra Vicente, Cortés Domínguez y Moreno Catena, Derecho Procesal Penal. 3 edición. Editorial Colex, Madrid España. 1999.

- Leone Giovanni, Tratado de Derecho Procesal Penal. Tomo 1. Doctrinas Generales, traducción de Sentís Melendo, Edición Jurídica, Europa América, Buenos Aires. 1963.

- Maeir Julio. Derecho Procesal Penal Argentino, 2 edición, Hammurabi, Buenos Aires, 1989.

- Ministerio Público. Pena y Estado, Editorial del Puerto s. r. 1. 1997, Buenos Aires.

- Ramos Méndez, Francisco. El proceso Penal: Lectura constitucional, J. M. Bosch editor, S. A. Barcelona, España, 1993.

- Tocora Fernando. Política Criminal en América Latina, ediciones librería del profesional, Bogotá Colombia, 1990.

- Vincenzo Manzini y otros. Tratado de Derecho Procesal Penal, Tomo II. Edición de Cultura Jurídica.

- Vives Antón Tomás. Ne Bis In Idem Procesal. Los principios del proceso penal. Consejo General del Poder Judicial. Madrid 1992. 
